\title{
How to avoid life-threatening complications following head and neck space infections: an algorithm-based approach to apply during times of emergency. When and why to hospitalise a neck infection patient
}

\author{
O GALLO, G MANNELLI, M S LAZIO, R SANTORO \\ Otolaryngology Clinic, Department of Surgery and Translational Medicine, University of Florence, Italy
}

\begin{abstract}
Background: Head and neck space infections present with a potential mortality rate of $40-50$ per cent. This paper proposes an algorithm-based management of head and neck space infection to prevent life-threatening events.

Methods: A total of 225 patients with head and neck space infection were prospectively analysed at our institution. An experimental scoring system determined the level of clinical risk for the development of major complications. Accordingly, patients were classified into three risk groups: low-, intermediate- and high-risk.

Results: Only intermediate- and high-risk patients were hospitalised. Intermediate-risk patients received intravenous medical therapy with daily re-evaluation; 18 of them required delayed surgery. Of the high-risk patients, three required immediate surgical treatment and five received delayed surgery, while in five cases medical therapy was the only treatment received. Low-risk patients were treated in an out-patient setting.

Conclusion: The algorithm-based management of head and neck space infection was successful in enabling the avoidance of lethal complications onset.
\end{abstract}

Key words: Infection; Algorithms; Emergencies; Otorhinolaryngologic Surgical Procedures

\section{Introduction}

Deep neck infections are defined as cellulitis or abscess formations of the fascial planes and potential spaces of the neck. ${ }^{1}$ They are unique among infectious diseases for their versatility and potential for severe complications if not identified. ${ }^{2-5}$ Most of them arise from foci in the mucosal surfaces of the upper aerodigestive tract or from a carious tooth. Usually the results of cultures are polymicrobial, and are often caused by oral bacteria, but streptococcus are the organisms most commonly cultured from deep neck abscesses. ${ }^{6}$

Generally, dental infections are the most common aetiological factors, followed by tonsillitis, a salivary stone, obstruction and branchial cyst infection. The neck spaces involved could be submandibular, peritonsillar, parapharyngeal, parotid, sublingual and submaxillary (Ludwig's angina), or retropharyngeal. Deep neck infections usually occur with considerable frequency, and their severity and extension can be underestimated. This makes them a challenging diagnostic entity for emergency physicians, paediatricians, otolaryngologists, and head and neck surgeons. ${ }^{7}$ The major symptoms of infections in different deep neck spaces are similar; thus, discovery of the underlying causative factors requires radiological study. Computed tomography $(\mathrm{CT})$ and magnetic resonance imaging can enable early detection of the true and specific cause of symptoms.

Although the incidence and severity of this disease have decreased dramatically since the introduction of antibiotics and improved dental care, deep neck infections continue to represent a challenge, with mortality rates still between 7 and 18 per cent, as recently reported. ${ }^{8-10}$

Treatment consists of adequate antimicrobial therapy, removal of causal teeth in patients with dental infection, surgical drainage of the abscess and management of complications. ${ }^{11}$ Although culture-guided antimicrobial therapy is advocated, the administration of empirical antibiotic treatment before the culture results become available is important. ${ }^{6,12}$ The cornerstones of treatment are securing the airway, providing efficient drainage, administering appropriate antibiotics and improving immunological status. ${ }^{13}$ 
Life-threatening complications of deep neck infections include upper airway obstruction, descending mediastinitis, pleural empyema, pericarditis, jugular vein thrombosis, ${ }^{3}$ septic shock, and carotid pseudoaneurysm or rupture. These manifestations are likely due to the increasing frequency of antibiotic resistance, particularly in immunocompromised patients or those of low socioeconomic status. When these complications occur, the mortality rate may reach 40-50 per cent. ${ }^{14,15}$

Hence, it is essential to identify critical cases where a well-timed intervention is mandatory. Early diagnosis and correct treatment planning can save a patient's life, and prevent complications of disease extension.

Our university ENT department covers a vast metropolitan area and its surroundings, which includes about one million inhabitants. Thus, this study reports on a consistent number of head and neck space infections occurring over a short period of time.

Our primary aim was to standardise a systematic institutional approach to head and neck space infection that could be helpful in the identification of cases at higher risk for the development of major, life-threatening complications. We created a scoring system that allowed us to establish the level of clinical risk and proposed an algorithm for the management of each patient's clinical condition. Additionally, we identified predisposing factors for the development of deep neck infections and other major complications.

\section{Materials and methods}

\section{Study population}

From January 2010 to December 2013, we recorded 21743 admissions to the emergency room of our university ENT department. Of these, 225 patients were referred with head and neck space infections (1.03 per cent of total accesses). A clinical diagnosis of head and neck space infection was considered whenever the spaces within the head and neck districts (masticatory, parotid, parapharyngeal, retropharyngeal and neck spaces), with the exception of the orbit, the sinonasal tract and the ear, were involved by a logistic process. The infection was categorised according to the primary source (dental infection, pharyngotonsillitis, parotitis, foreign bodies) and the involved spaces. Patients with involvement of two or more spaces were classified as having multiple space infections.

All head and neck space infection patients were immediately evaluated with a scoring system, to discriminate between patients who required hospitalisation and those who did not. A numerical value between 0 and 3 was assigned to each of the following clinical parameters: airway obstruction, neck involvement, mouth opening, swallowing and previous antibiotics (Table I). The final score was the sum of each single value. Patients with a final global score of $0-5$ were considered to have a low-risk for life-threatening events, and were therefore managed in an out-patient setting. Patients with a score of 6-10 were considered to have an intermediate-risk and those with a score of 11-15 were considered as high-risk; patients with a score over 6 required hospitalisation.

Patients presenting with isolated critical airway obstruction, as reflected by a reduction in more than 50 per cent of their pharynx and/or larynx airway space for example, or those presenting with indirect signs of dyspnoea such as tirage and cornage, were hospitalised for at least 24-48 hours in order to manage and treat their respiratory distress.

Patients presenting with initial peritonsillar cellulitis, who did not require surgical incision and who were treated with broad-spectrum intramuscular antibiotic or corticosteroid therapy, were excluded from this study. However, we included patients with an isolated peritonsillar abscess even without parapharyngeal space involvement. They were re-assessed as low-risk after prompt surgical incision of the pus collection in an out-patient setting, and none of these patients required delayed admission.

The protocol for the prospective study was approved by our institutional review board. Patients were given extensive information about the procedures they were about to undergo, including the potential surgery, and all the participants signed an informed consent agreement.

All 225 cases were managed following an algorithm that was coded for the purposes of this study (Figure 1).

The following clinical data were recorded (after patient consent was obtained): physiological signs of sepsis, such as high fever, high white blood cell count, tachycardia, elevated erythrocyte sedimentation rate, and increased $\mathrm{C}$-reactive protein and fibrinogen levels; associated systemic diseases; bacteriology findings; imaging findings; source and site of infection; length of hospitalisation in admitted patients; medical and surgical treatment; complications; and outcome.

\section{Aetiology and site}

The primary site of infection was identified in 215 out of 225 cases ( 95.55 per cent). Pharyngotonsillitis represented the most common primary source $(n=136$; 60.44 per cent), causing 127 (56.44 per cent) isolated peritonsillar abscesses, 6 (2.67 per cent) peritonsillar or parapharyngeal space abscesses, and 3 (1.33 per cent) multiple site abscesses (peritonsillar-parapharyngeal-laterocervical). Dental infection was identified as the primary source in 66 cases (29.33 per cent), causing 42 (18.67 per cent) submandibular abscesses, 5 (2.22 per cent) submental abscesses, 6 (2.67 per cent) Ludwig's anginas, 8 (3.55 per cent) multiple site abscesses (submandibular and laterocervical, submandibular and submental, submandibular and parapharyngeal) and five (2.22 per cent) masticatory space abscesses. Neglected foreign bodies caused one ( 0.89 per cent) peritonsillar abscess and one $(0.89$ per cent) tongue base abscess. Parotitis caused a parotid abscess in eight cases (3.56 per cent). Adjuvant 


\begin{tabular}{|c|c|c|c|c|}
\hline \multicolumn{5}{|c|}{ RISK ASSESSMENT SCALE } \\
\hline \multirow[t]{2}{*}{ Parameter } & \multicolumn{4}{|c|}{ Score } \\
\hline & 0 & 1 & 2 & 3 \\
\hline $\begin{array}{l}\text { Airway } \\
\text { obstruction }\end{array}$ & Fibre-optic findings normal & $\begin{array}{l}\leq 30 \% \text {, with no tirage } \\
\quad \& \text { no cornage }\end{array}$ & $\begin{array}{l}31-50 \% \text {, with no tirage } \\
\& \text { no cornage }\end{array}$ & $\begin{array}{l}>50 \%, \text { or }<50 \% \text { with tirage } \& \\
\quad \text { cornage }\end{array}$ \\
\hline $\begin{array}{l}\text { Neck } \\
\text { involvement }\end{array}$ & $\begin{array}{l}\text { Isolated } \\
\text { peritonsillar abscess }\end{array}$ & $\begin{array}{l}\text { Submental \&/or } \\
\text { submandibular }\end{array}$ & $\begin{array}{l}\text { Parapharyngeal or cervical } \\
\text { (levels I, II, III, Va) }\end{array}$ & $\begin{array}{l}\text { Parapharyngeal \& cervical (levels I, } \\
\text { II, III, Va), or cervical (IV, Vb, } \\
\text { VI) }\end{array}$ \\
\hline $\begin{array}{l}\text { Mouth } \\
\text { opening }\end{array}$ & Normal & $>1.5 \mathrm{~cm}$ & $\leq 1.5 \mathrm{~cm}$ & Tight trismus \\
\hline Swallowing & Normal & Impaired for solids & $\begin{array}{l}\text { Impossible for solids, } \\
\text { impaired for fluids }\end{array}$ & Impossible \\
\hline $\begin{array}{l}\text { Previous } \\
\text { antibiotics }\end{array}$ & None & Oral & Intramuscular & Intravenous \\
\hline
\end{tabular}

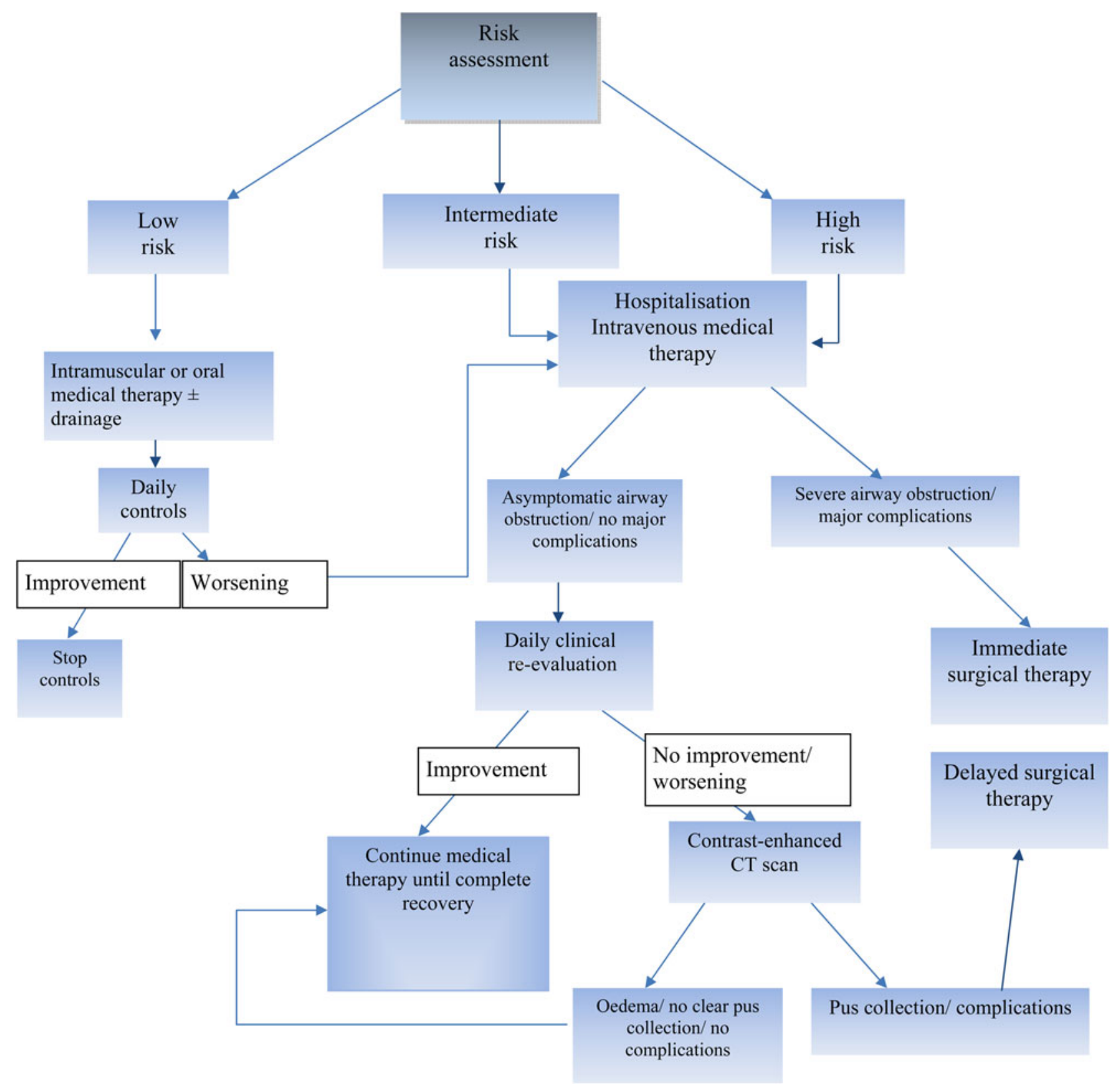

FIG. 1

Management algorithm for head and neck space infection based on risk assessment. CT = computed tomography 
radiotherapy caused three ( 1.33 per cent) laterocervical abscesses. In 10 cases (4.44 per cent), the aetiology remained unknown: 7 patients (3.11 per cent) presented with a laterocervical abscess and 3 (1.33 per cent) presented with an anterior neck abscess.

\section{Co-morbidity}

Thirteen patients (5.77 per cent) had underlying systemic diseases: nine were affected by diabetes mellitus type 1 , one had liver dysfunction hepatitis $\mathrm{C}$ virus (HCV)-related disease, one presented with ulcerative colitis, and two were affected by both diabetes mellitus type 1 and HCV.

\section{Microbiology}

The results of pus cultures were available for 58 patients ( 25.7 per cent): 26 patients who were admitted and operated on, and 32 patients who were not admitted. The cultures in 44 cases ( 75.8 per cent) were polymicrobial, including oral cavity aerobic and anaerobic organisms. In nine cases (15.5 per cent), Streptococcus pyogenes was the main micro-organism found, in four cases (6.9 per cent) it was prevotella and in one case (1.7 per cent) it was Enterococcus faecalis.

All 225 head and neck space infection patients received empirical broad-spectrum antimicrobial therapy (i.e. amoxicillin and clavulanic acid or cephalosporins, third generation, at least for 10 days), with re-evaluation in the 58 cases after a review of the microbiological results. Proper adjustment was required in six cases (i.e. piperacillin and tazobactam).

\section{Statistical analysis}

The following parameters were analysed in order to identify potential risk factors for major complications: gender, age, body temperature, leukocytosis, concomitant diseases, deep neck spaces involvement (i.e. laterocervical or parapharyngeal space), therapy type and hospitalisation length. Univariate and logistic regression multivariate analyses were used to identify independent risk factors for complications. Statistical analysis was performed using Stata software, version 9.1 (Stata, College Station, Texas, USA). A $p$-value of 0.05 or less was considered statistically significant.

\section{Results}

\section{Study population}

Among 225 patients presenting with head and neck space infection, 113 (50.22 per cent) were female and 112 (49.78 per cent) were male. Patients were aged 8-96 years, with a peak of incidence in the fourth decade of life.

Following the first assessment, 167 patients (74.22 per cent) were classified as low-risk and were followed up in an out-patient setting: 88 received home-based therapy, and 79 underwent peritonsillar abscess incision with drainage of purulent collection as out-patients. None of the patients were subsequently hospitalised and/or subjected to surgical treatment under general anaesthesia. The 45 patients classified as intermediaterisk and the remaining 13 high-risk cases were all hospitalised. No patients presented with isolated critical airway obstruction (scored as 3 as per our head and neck space infection scale for risk assessment).

In all admitted patients, intravenous broad spectrum antibiotic therapy was started immediately, and a contrast-enhanced head, neck and thorax CT scan was performed.

Intermediate-risk patients were re-evaluated 24 hours after admission. If a clinical response and a lower score were observed, further re-evaluation after 24 hours, with no other intervention or investigation, was indicated ( $n=27 ; 60$ per cent). If a patient's symptoms and signs did not improve and/or worsened despite infusion therapy, a contrast-enhanced CT scan was performed, and patients were submitted to surgical drainage when colliquative pus collection was demonstrated $(n=18 ; 40$ per cent). An intermediate-risk patient, suffering from diabetes mellitus and HCV liver failure, developed sepsis despite surgical drainage of the abscess. This patient was transferred to the intensive care unit and died after 22 days due to the onset of septic thrombophlebitis of the jugular vein and thrombosis of the intracranial vessels.

High-risk patients were subjected to immediate surgery only in 3 out of 13 cases ( 23 per cent). These patients showed airway obstruction associated with the involvement of multiple laterocervical spaces; two patients presented with initial mediastinitis, as shown on the CT scan. Intravenous medical therapy was administered to the remaining 10 high-risk patients ( 77 per cent), and they all were re-evaluated after 24 hours. Fifty per cent of these patients underwent delayed surgery; the remaining five high-risk patients continued medical therapy until recovery was complete.

The surgical treatment performed on admitted patients is summarised in Table II.

\section{Complications and outcomes}

The 3 patients with complications were all male, with an average age of 55 years, and the abscesses involved multiple low laterocervical spaces. Tracheostomy was performed in all three patients to ensure airway patency. Two of the patients were further observed in the intensive care unit. Thoracic drainage was

\begin{tabular}{lc}
\multicolumn{3}{c}{ TABLE II } \\
\multicolumn{2}{c}{$\begin{array}{c}\text { SURGICAL APPROACH IN PATIENTS ADMITTED AND } \\
\text { OPERATED ON }\end{array}$} \\
\hline Surgical approach & Patients $(n(\%))$ \\
\hline Incision of mouth floor & $10(38.47)$ \\
Cervicotomic & $11(42.3)$ \\
Needle aspiration & $2(7.69)$ \\
Wharton duct marsupialisation & $2(7.69)$ \\
Endoscopic drainage & $1(3.85)$ \\
\hline
\end{tabular}

Total $n=26$ 


\section{TABLE III}

\begin{tabular}{lcc}
$\begin{array}{c}\text { UNIVARIATE AND MULTIVARIATE ANALYSIS FOR LIFE- } \\
\text { THREATENING COMPLICATIONS }\end{array}$ \\
\hline Factor & $\begin{array}{c}\text { Univariate } \\
(p \text {-value })\end{array}$ & $\begin{array}{c}\text { Multivariate } \\
(p \text {-value })\end{array}$ \\
\hline Sex: male $v$ s female & 0.243 & 0.27 \\
Age $>45$ years & 0.569 & 0.08 \\
Temperature $>37.5^{\circ} \mathrm{C}$ & 0.569 & 0.89 \\
Leucocytosis $>12500 / \mathrm{mm}^{3}$ & 1.000 & 0.21 \\
Diabetes mellitus & 0.086 & 0.007 \\
Laterocervical site & 0.014 & 0.02 \\
Mono- $v s$ poly-antibiotic therapy & 1.000 & 0.79 \\
Surgery $v$ medical therapy & 1.000 & 0.99 \\
Hospitalisation days & 0.152 & 0.11 \\
\hline
\end{tabular}

performed in association with cervicotomic drainage in two cases of mediastinitis. Finally, one patient affected by diabetes mellitus and HCV-related liver dysfunction developed sepsis despite successful bilateral submandibular abscess drainage. He was admitted to the intensive care unit and died after 22 days due to the onset of internal jugular vein (IJV) thrombosis. All other patients were discharged in a stable condition after a mean hospitalisation length of 9.38 days (range, 2-33 days).

Univariate analysis was performed to assess factors associated with life-threatening complications. This indicated that laterocervical space involvement was the strongest independent predictor of severe complications ( $p=0.014$; Table III). The only other variable which showed a trend towards statistical significance was diabetes.

On multivariate analysis, diabetes mellitus and laterocervical space involvement were the strongest independent predictors of complications $(p=0.007$ and $p=0.02$, respectively) (Table III).

\section{Discussion}

The principal aim of our study was to standardise an institutional systematic approach to the management of deep neck infections via evaluation of the clinical risk for life-threatening complications. Based on the literature and our experiences of ENT urgencies or emergencies, we have proposed a diagnostic-therapeutic algorithm for the management of these diseases.

Of the cases analysed, 167 patients had a low risk for major complications and they were managed in an outpatient setting; none of them were hospitalised or underwent surgery. Of the 45 patients with an intermediate risk, 27 were cured by medical treatment only; the remaining patients required delayed surgery. Despite successful drainage of a bilateral submandibular abscess, one patient, affected by diabetes mellitus and HCV-related liver dysfunction, developed sepsis and died after 22 days in the intensive care unit due to the onset of IJV thrombosis. The diabetes mellitus and HCV-related liver dysfunction, described in literature as predictors of major complication development, ${ }^{14-16}$ may have created a multi-systemic infectious process that killed the patient. Finally, of the 13 patients with a high risk, 3 patients with major complications were submitted immediately to surgery, 5 were treated with medical treatment only and 5 underwent surgery after medical treatment. None of the patients had isolated critical airway obstruction or indirect signs of dyspnoea; it is strongly recommended that patients presenting with these conditions, with or without physiological signs of sepsis, are hospitalised.

Our secondary aim was to identify risk factors for the development of major complications, in order to recognise and treat patients presenting with a high risk for lifethreatening events. It is widely known that delayed diagnosis and inadequate mediastinum drainage are important factors associated with an increased incidence in mortality. ${ }^{14,16-19}$ In our study, the mortality rate was 0.44 per cent, and the only case of death was not related to delayed diagnosis but to the co-existence of severe co-morbidities known to worsen the prognosis of deep neck infections. ${ }^{16}$ Multivariate analysis showed that patients with diabetes mellitus and a laterocervical abscess had a higher risk of developing complications. In our series, 13 patients (5.77 per cent) presented with different co-morbidities, with diabetes mellitus being the most common ( $n=9 ; 69.23$ per cent).

We found a higher incidence of deep neck infections between the second and fourth decade of life. The incidence in males and females was similar. This is in contrast with previous studies, which showed a predominance of male gender of 2:1. ${ }^{14,17}$ Regarding infection sites, we observed a predominance of peritonsillar abscess $(n=127 ; 56.44$ per cent) and only 1 case required surgery, with 66 cases $(29.33$ per cent) of odontogenic abscess. In 76 per cent of cases, the culture test showed the predominance of aerobic and anaerobic micro-organisms of the oral cavity, in agreement with data reported in the literature. ${ }^{19,20}$

A CT scan with contrast was our diagnostic method of choice, as it allows the identification of fluid collections, gas presence, tissue thickening and enhancement with the loss of normal fascial plans. ${ }^{21}$ It plays a crucial role in shaping the involved areas and monitoring the development of the infection, with the intent to plan the proper surgical approach. ${ }^{22-24}$ Ultrasound is another useful method in guiding diagnostic needle aspiration and therapeutic drainage, in cases where there is no immediate airway compromise. In two cases, percutaneous drainage under ultrasound guidance was performed. Panoramic radiography is quick to perform, useful in odontogenic infections and allows identification of the dental element that needs to be removed to completely recover from the infection.

Incision and drainage of abscesses represents the 'gold standard' in the treatment of deep neck infections. ${ }^{25}$ Recently, the use of vacuum-assisted closure has been proposed over the use of common drainage tubes after surgical evacuation. This has superior efficacy in terms of secretion drainage, promoting the hypervascularity of the surgical bed, thus avoiding the need for surgical revision of the most extended abscesses. ${ }^{26}$ 
Tracheostomy performed under local anaesthesia is widely considered the standard practice in airway management for patients with deep neck infections. ${ }^{27} \mathrm{We}$ performed tracheostomy under general anaesthesia in three patients with laterocervical abscesses after nasotracheal intubation. We firmly believe that tracheostomy should be avoided as much as possible, and reserved only for cases of severe and reduced breathing space, to avoid the spread of infection through the tracheostomy site. In fact, all patients with moderate airway obstruction, after surgery and evacuation of the abscess, showed significant improvement of the breathing space.

Medical therapy mainly comprised amoxicillin and clavulanic acid or cephalosporins, third generation or poly-antibiotic. First, this heterogeneity in the choice of medical therapy reflects individual preferences within our team of specialists and residents. Second, for patients allergic to beta-lactam antibiotics, it has not been possible to prescribe the first-line therapy of penicillin or cephalosporin.

- There are typically no standardised criteria for hospitalisation of head and neck infection patients

- However, our diagnostic and therapeutic scheme enabled complete compliance with the proposed strategy

- Our clinical risk rating scale has proved easy to use

- It is effective in discriminating low-risk patients, managed as out-patients, from intermediate- and high-risk patients who require hospitalisation

In conclusion, for the best management of the deep neck infections, a good understanding of critical cases and the prevention of major complications is essential. Any delay in diagnosis can lead to a wrong choice of treatment and modify the outcome. ${ }^{28,29}$ Although the right management of deep neck infections remains a constant challenge, this study offers an effective system of clinical risk assessment. This system accounts for the seriousness of this medical condition, and aids diagnosis and planning of the most appropriate therapeutic treatment, with important prognostic implications.

\section{References}

1 Sakarya EU, Kulduk E, Gundogan O, Soy FK, Dundar R, Kilavuz AE et al. Clinical features of deep neck infection: analysis of 77 patients. Kulak Burun Bogaz Ihtis Derg 2015;25:102-8

2 Ovassapian A, Tuncbilek M, Wentzel EK, Joshi CW. Airway management in adult patients with deep neck infections: a case series and review of the literature. Anesth Analg 2005; 100:585-9

3 Miller B, Khalifa Y, Feldon SE, Friedman DI. Lemierre syndrome causing bilateral cavernous sinus thrombosis. J Neuroophthalmol 2012;32:341-4
4 Colmenero Ruiz CC, Labajo AD, Yanez Vilas IY, Paniagua J. Thoracic complications of deeply situated serious neck infections. J Craniomaxillofac Surg 1993;21:76-81

5 Levine TM, Wurster CF, Krespi YP. Mediastinitis occurring as a complication of odontogenic infection. Laryngoscope 1986;94: 747-50

6 Huang TT, Tseng FY, Yeh TH, Hsu CJ, Cen YS. Factors affecting the bacteriology of deep neck infection: a retrospective study of 128 patients. Acta Otolaryngol 2006;126:396-401

7 Brito TP, Hazboun IM, Fernandes FL, Bento LR, Zappelini CE, Chone CT et al. Deep neck abscesses: study of 101 cases. Braz J Otorhinolaryngol 2017;83:341-8

8 Meher R, Jain A, Sabharwal A, Gupta B, Singh I, Agarwal AK. Deep neck abscess: a prospective study of 54 cases. J Laryngol Otol 2005;119:299-302

9 Reynolds SC, Chow AW. Life-threatening infections of the parapharyngeal and deep fascial spaces of the head and neck. Infect Dis Clin North Am 2007;21:557-76

10 Beck HJ, Salassa JR, McCaffey T, Hermans PE. Life-threatening soft tissue infections of the neck. Laryngoscope 1984;94: 354-61

11 Uluibau IC, Jaunay T, Goss AN. Severe odontogenic infections. Aust Dent J 2005;50:S74-81

12 Lee YQ, Kanagalingam J. Bacteriology of deep neck abscesses: a retrospective review of 96 consecutive cases. Singapore Med J 2011;52:351-5

13 Vieira F, Allen SM, Stocks RM, Thompson JW. Deep neck infection. Otolaryngol Clin North Am 2008;41:459-83

14 Lin HT, Tsai CS, Chen YL, Liang JG. Influence of diabetes mellitus on deep neck infection. J Laryngol Otol 2006;120: 650-4

15 Oliver ER, Boyd Gillespie M. Deep neck space infections. In: Cummings Flint PW, Haughey BH et al., eds. Otolaryngology Head and Neck Surgery, 5th edn. St Louis: Mosby, 2010;201-8

16 Wang LF, Tai CF, Kuo WR, Chien CY. Predisposing factors of complicated deep neck infections: 12-year experience at a single institution. J Otolaryngol Head Neck Surg 2010;39: 335-41

17 Yellon RF. Head and neck space infections. In: Bluestone CD, Casselbrant ML, Stool SE et al., eds. Pediatric Otolaryngology, volume 2, 4th edn. Philadelphia: Saunders, 2003;1681-701

18 Sueara AB, Gonçalves AJ, Alcadipani FA, Kavabata NK, Menezes MB. Deep neck infection: analysis of 80 cases. Braz J Otorhinolaryngol 2008;74:253-9

19 Bartlett JG, Gorbach SL. Anaerobic infections of the head and neck. Otolaryngol Clin North Am 1976;9:655-78

20 Brook I. Microbiology and management of peritonsillar, retropharyngeal and parapharyngeal abscesses. J Oral Maxillofac Surg 2004;62:1545-50

21 Boscolo-Rizzo P, Marchiori C, Zanetti F, Vaglia A, Da Mosto MC. Conservative management of deep neck abscesses in adults: the importance of CECT findings. Otolaryngol Head Neck Surg 2006;135:894-9

22 Daramola OO, Flanagan CE, Maisel RH, Orland RM. Diagnosis and treatment of deep neck space abscesses. Otolaryngol Head Neck Surg 2009;141:123-30

23 Nagy M, Backstrom J. Comparison of the sensitivity of lateral neck radiographs and computed tomography scanning in pediatric deep-neck infections. Laryngoscope 1999;109:775-9

24 Crespo AN, Chone CT, Fonseca AS. Clinical versus computed tomography evaluation in the diagnosis and management of deep neck infection. Sao Paulo Med J 2004;122:259-63

25 Boscolo-Rizzo P, Stellin M, Muzzi E, Mantovani M, Fuson R, Lupato V et al. Deep neck infections: a study of 365 cases highlighting recommendations for management and treatment. Eur Arch Otorhinolaryngol 2012;269:1241-9

26 Gallo O, Deganello A, Meccariello G, Spina R, Peris A. Vacuum-assisted closure for managing neck abscesses involving the mediastinum. Laryngoscope 2012;122:785-8

27 Yuen H, Loy A, Johari S. Urgent awake tracheotomy for impending airway obstruction. Otolaryngol Head Neck Surg 2007;136:838-42

28 Boscolo-Rizzo P, Da Mosto MC. Submandibular space infection: a potentially lethal infection. Int $J$ Infect Dis 2009;13: 327-33

29 Boscolo-Rizzo P, Marchiori C, Montolli F, Vaglia A, Da Mosto MC. Deep neck infections: a constant challenge. ORL J Otorhinolaryngol Relat Spec 2006;68:259-65 
Address for correspondence:

Dr Giuditta Mannelli,

Clinic of Otorhinolaryngology Head and Neck Surgery,

Department of Surgery and Translational Medicine,

University of Florence,

Azienda Ospedaliera Universitaria Careggi,

Via Largo Brambilla 3,

Florence 50134, Italy
E-mail: mannelli.giuditta@gmail.com

Dr G Mannelli takes responsibility for the integrity of the content of the paper

Competing interests: None declared 